\title{
OPEN Author Correction: An upper bound for the background rate of human extinction
}

\author{
Andrew E. Snyder-Beattie, Toby Ord (D) \& Michael B. Bonsall (1D \\ Correction to: Scientific Reports https://doi.org/10.1038/s41598-019-47540-7, published online 30 July 2019 \\ The Acknowledgements section in this Article is incomplete. \\ "We thank Carl Shulman, Dave Waltham, and Nick Bostrom for feedback and comments. This work was funded \\ by Jaan Tallinn and the Open Philanthropy Project." \\ should read:
}

"We thank Carl Shulman, Dave Waltham, and Nick Bostrom for feedback and comments. This work was funded by Jaan Tallinn and the Open Philanthropy Project. This project has received funding from the European Research Council (ERC) under the European Union's Horizon 2020 research and innovation programme (grant agreement No 669751)."

(c) Open Access This article is licensed under a Creative Commons Attribution 4.0 International Cicense, which permits use, sharing, adaptation, distribution and reproduction in any medium or format, as long as you give appropriate credit to the original author(s) and the source, provide a link to the Creative Commons license, and indicate if changes were made. The images or other third party material in this article are included in the article's Creative Commons license, unless indicated otherwise in a credit line to the material. If material is not included in the article's Creative Commons license and your intended use is not permitted by statutory regulation or exceeds the permitted use, you will need to obtain permission directly from the copyright holder. To view a copy of this license, visit http://creativecommons.org/licenses/by/4.0/.

(C) The Author(s) 2019 